\title{
Comparison of Gas-liquid and High-performance Liquid Chromatography, and Mass Spectrometry, for the Detection of Organic Acids in Culture Media of Azospirillum brasilense and Desulfovibrio desulfuricans
}

\author{
By W. HSIAO-TSU LOH, $†$ NICHOLAS SANTORO $\ddagger$ ROBERT H. MILLER \\ AND OLLI H. TUOVINEN* \\ Department of Microbiology, The Ohio State University, Columbus, Ohio 43210, USA
}

(Received 5 September 1983)

\begin{abstract}
Gas-liquid chromatography (GLC) and high-performance liquid chromatography (HPLC) were used to separate organic acids in spent culture media. Organic acid components were identified on the basis of their retention times and confirmed by gas chromatography/mass spectrometry (GLC/MS). The sensitivity of the analytical procedures varied considerably with each organic acid. GLC analysis of spent culture media esterified by the $\mathrm{H}_{2} \mathrm{SO}_{4} /$ methanol procedure failed to detect fumarate, malate and lactate. The $\mathrm{BF}_{3} /$ methanol derivatization was particularly sensitive to pyruvate and lactate. GLC/MS, using the $\mathrm{BF}_{3} /$ methanol technique, was insensitive to acetate. Cation-exchange HPLC, using a Bio-Rad acid analysis column, did not require prior derivatization of the sample, and proved to be a rapid and non-destructive assay technique for organic acids. This procedure was used to analyse the spent culture media of aerobically grown Azospirillum brasilense and those of Desulfovibrio desulfuricans grown on pyruvate fermentatively or with sulphate as the electron acceptor. Organic acid profiles of the spent culture media obtained by cation-exchange HPLC analysis were compared with those obtained by GLC analysis using both the $\mathrm{H}_{2} \mathrm{SO}_{4} /$ methanol and the $\mathrm{BF}_{3} /$ methanol esterification procedures.
\end{abstract}

\section{INTRODUCTION}

The study of metabolic pathways in bacteria often requires an analysis of the end products of sugar catabolism. During anaerobic metabolism, these acid end products are usually fermentation acids, although tricarboxylic acid (TCA) cycle intermediates may also accumulate. A variety of methods have been developed for the separation of these metabolites, including silica gel chromatography, gas-liquid chromatography (GLC), and high-performance liquid chromatography (HPLC).

Organic acids were initially separated by silica gel chromatography on a chloroform $/ 5 \%(\mathrm{v} / \mathrm{v})$ tert-butanol gradient (Frohman et al., 1951). To increase the sensitivity of the assay, erythrocytes were incubated with a ${ }^{14} \mathrm{C}$-labelled substrate (Dajani \& Orten, 1958). The radioactive products of catabolism were collected and identified as tricarboxylic acids on the basis of previously determined elution rates and quantified by liquid scintillation counting.

Other workers have subsequently applied GLC in the detection and identification of organic acids. The major drawback to this approach is the need for a derivatization step, without which some organic acids are insufficiently stable and volatile for GLC analysis. In addition, formic acid responds poorly to flame ionization detection (FID) without prior derivatization (Lambert

† Present address: Department of Biology, University of Virginia, Charlottesville, Virginia 22901, USA.

$\ddagger$ Present address: Department of Microbiology, University of Illinois, Urbana, Illinois 61801, USA.

$\S$ Present address: Department of Soil Sciences, North Carolina State University, Raleigh, North Carolina 27650, USA.

Abbreviations: FID, flame ionization detection/detector; TCD, thermal conductivity detection/detector. 
\& Moss, 1972). Underivatized polyfunctional acids often adsorb to both the wall and the solid support of the column (Knapp, 1979). Holdeman et al. (1977) developed a rapid and inexpensive derivatization procedure which involved heating organic acid samples in sulphuric acid and methanol. The methyl esters generated by the $\mathrm{H}_{2} \mathrm{SO}_{4} /$ methanol method could be separated by GLC and identified with thermal conductivity detection (TCD). $\mathrm{A} \mathrm{BF}_{3} /$ methanol procedure has also been developed for esterification of TCA cycle and fermentation acids (Hautala \& Weaver, 1969). Harmon \& Doelle (1969) reported that the sensitivity of FID for the identification of seven organic acids with this derivatization procedure approached $0 \cdot 1 \mu \mathrm{g}$.

Disadvantages of both the $\mathrm{BF}_{3} /$ methanol and $\mathrm{H}_{2} \mathrm{SO}_{4}$ /methanol derivatization reactions include sample loss during methylation and the formation of multiple derivatives of oxo acids. Oxaloacetate, 2-oxoglutarate and pyruvate are especially labile. Some of the problems associated with these methylation procedures were partially resolved by a methoxylamine hydrochloride treatment followed by silylation with bis-trimethylsilyltrifluoroacetamide (Horning et al., 1968). However, the resulting trimethylsilyl oxime derivatives of oxo carboxylic acids often occur as two stereoisomeric oximes and produce two peaks in the resulting chromatograms. In addition, the exacting conditions of derivatization required by this procedure severely reduce its application.

The definitive approach to the identification of organic acids has been through mass spectral (MS) analysis, using electron impact, chemical ionization and pyrolysis MS. The latter technique has been particularly useful in the diagnosis of certain urinary disorders (Meuzelaar $e t$ al., 1980). However, the problems which are associated with derivatization for GLC separation are again encountered. Therefore, many workers have resorted to liquid chromatography techniques in order to avoid generating artefacts of derivatization. A further deterrent to the use of GLC/MS for routine analysis of organic acids is the cost of the instruments.

Turkelson \& Richards (1978) were able to separate all TCA cycle acids on a cation-exchange resin by eluting the column with dilute $\mathrm{HCl}$. A modification of the above procedure was used to separate organic acids in dairy products by HPLC (Marsili et al., 1981). Many fatty acids and a few TCA cycle acids were detected. Rajakylä (1981) reported separation of gluconic acid, its sodium salt, arabidonic acid and formic acid by cation-exchange HPLC.

A similar procedure was developed for the analysis of fatty acids in anaerobic culture media (Guerrant et al., 1982). Twenty-five short-chain fatty acids and some TCA cycle and fermentation acids were identified. With the exception of fumarate, however, the results of HPLC analysis were not confirmed by an alternative technique.

Buchanan \& Thoene (1982) developed a two-dimensional HPLC procedure to improve resolution of urinary carboxylic acids. Saturated acids, 2-oxo acids and hydroxy acids in urine samples were chromatographed on a cation-exchange HPLC column joined in series with an octadecylsilane reverse-phase column. Separation of organic acid samples through two HPLC columns, however, is both expensive and time consuming, requiring a $2 \mathrm{~h}$ elution for each sample.

Bocek et al. (1976) have reported the separation of TCA cycle acids by capillary isotachophoresis. In order to avoid interference by dissolved $\mathrm{CO}_{2}$, electrophoretic separation must be conducted below pH 6.2. Under these conditions, lactate, malate, citrate and isocitrate were poorly resolved as distinct peaks. The limits of sensitivity of this technique range from $10^{-3}$ to $10^{-4} \mathrm{M}$, with each electrophoretic run lasting only $4 \mathrm{~min}$. This method has proved effective in identifying major acid components in commercially prepared fruit products (Delmotte, 1979). Although this is a powerful separation technique, commercial instrumentation is not available (Jorgenson \& Lukacs, 1983).

We report here a rapid and highly reproducible procedure for the separation and identification of all TCA cycle and fermentation acids using a cation-exchange HPLC column. This method was applied to the identification of these acids in spent culture media of Azospirillum brasilense and Desulfovibrio desulfuricans. The results were compared to those obtained by GLC, using both the $\mathrm{H}_{2} \mathrm{SO}_{4} /$ methanol and $\mathrm{BF}_{3} /$ methanol derivatization procedures. The sensitivity and accuracy of each of these techniques were tested against GLC/MS analysis. 


\section{METHODS}

Culture of micro-organisms. Azospirillum brasilense Sp7 (ATCC 29145) was cultured in liquid medium containing $\left(1^{-1}\right)$ : succinic acid, $7.65 \mathrm{~g} ; \mathrm{NH}_{4} \mathrm{Cl}, 1.34 \mathrm{~g} ; \mathrm{K}_{2} \mathrm{HPO}_{4}, 0.4 \mathrm{~g} ; \mathrm{KH}_{2} \mathrm{PO}_{4}, 0.2 \mathrm{~g} ; \mathrm{MgSO}_{4} .7 \mathrm{H}_{2} \mathrm{O}, 0.2 \mathrm{~g} ; \mathrm{NaCl}, 0.1 \mathrm{~g}$; $\mathrm{CaCl}_{2} .2 \mathrm{H}_{2} \mathrm{O}, 26.5 \mathrm{mg} ; \mathrm{FeSO}_{4} .7 \mathrm{H}_{2} \mathrm{O}, 17 \mathrm{mg} ; \mathrm{MnSO}_{4} . \mathrm{H}_{2} \mathrm{O}, 3.9 \mathrm{mg} ; \mathrm{H}_{3} \mathrm{BO}_{3}, 2.8 \mathrm{mg} ; \mathrm{NaMoO}_{4} .2 \mathrm{H}_{2} \mathrm{O}$, $2 \mathrm{mg}$; $\mathrm{CuSO}_{4}, 0.34 \mathrm{mg} ; \mathrm{ZnSO}_{4}, 0.24 \mathrm{mg}$; $\mathrm{Na}_{2}$ EDTA, $23 \mathrm{mg}$. The medium was adjusted to pH 6.8 and filter sterilized. The bacteria were grown at $37^{\circ} \mathrm{C}$ on a rotary shaker set at 120 r.p.m. Cells were harvested by centrifugation $(7500 \mathrm{~g}$ for $10 \mathrm{~min})$ at the mid-exponential growth phase.

Desulfovibrio desulfuricans (derived from ATCC 13541) was cultured in the medium of Brandis \& Thauer (1981) with pyruvate $\left(3.5 \mathrm{~g} \mathrm{l}^{-1}\right)$ instead of lactate as a carbon source. The basal salts, vitamins and trace minerals were autoclaved. Solutions of pyruvate and reducing agents were filter sterilized and aseptically added by syringe. Growth was initiated at $30^{\circ} \mathrm{C}$ in 2-litre Square-Pak flasks (American Sterilizer Co., Erie, PA, USA) containing 1 litre medium, according to the procedure developed by Behbehani et al. (1982). For respiratory growth, ascorbate and thioglycollate (both at $1.0 \mathrm{~g} \mathrm{1}^{-1}$ ) were used as reducing agents. For fermentative growth, $\left(\mathrm{NH}_{4}\right)_{2} \mathrm{SO}_{4}$ was replaced by $\mathrm{NH}_{4} \mathrm{Cl}\left(1.0 \mathrm{~g} \mathrm{l}^{-1}\right)$, and sodium sulphide $(0 \cdot 1 \mathrm{mM})$ was used as the sole reducing agent. Cells were harvested at the mid-exponential growth phase by centrifugation $(10000 \mathrm{~g}$ for $10 \mathrm{~min})$. Samples of the culture media were stored at $4^{\circ} \mathrm{C}$ until analysed.

High-performance liquid chromatography. Organic acid samples were separated on an Aminex HPX-87H $(300 \times$ $7.8 \mathrm{~mm}$ ) organic acid analysis column (Bio-Rad). The dilute sulphuric acid mobile phase $(0.001 \mathrm{M}, 0.00225 \mathrm{M}$, $0.0045 \mathrm{M}$ ) was prepared from reagent-grade $\mathrm{H}_{2} \mathrm{SO}_{4}$ and $\mathrm{HPLC}$-grade water (Fisher Scientific, Cincinnati, $\mathrm{OH}$, USA), filtered through Nuclepore $0.2 \mu \mathrm{m}$ polycarbonate membrane filters, and degassed. The column was placed inside a glass jacket insulated with asbestos gauze. Temperature control was maintained by circulating automotive antifreeze (Prestone, diluted $1: 1$ with water) through the jacket with a thermostatically controlled circulating water bath. An Altex pumping system, equipped with a manual $20 \mu$ loop injector and controlled by an Altex model 420 microprocessor controller/programmer (Altex Scientific, Berkeley, CA, USA) was used for isocratic separation. The pump pressure ranged from $6.9 \mathrm{MPa}$ at $85^{\circ} \mathrm{C}$ to $8.3 \mathrm{MPa}$ when the column temperature was lowered to $25^{\circ} \mathrm{C}$. The mobile phase was maintained at the same temperature as the column for each experiment.

The column effluent (flow rate $0.8 \mathrm{ml} \mathrm{min}^{-1}$ ) was monitored at $210 \mathrm{~nm}$ with a Hitachi $100-40$ spectrometer (Hitachi, Tokyo, Japan) adapted with an Altex 155-00 (20 1$)$ flow cell. Chromatograms were recorded with a single-channel chart recorder. The samples were filtered through Millipore Millex-HA $0.45 \mu \mathrm{m}$ filter units before use. All glassware and syringes were rinsed with HPLC-grade water. Before using the system $50 \%(\mathrm{v} / \mathrm{v})$ nitric acid (reagent grade) was pumped through at $1 \mathrm{ml} \mathrm{min}^{-1}$ at $80^{\circ} \mathrm{C}$ for $20 \mathrm{~min}$ to remove residual contaminants. The column was removed during this cleaning procedure.

Gas chromatography. A Varian model 3700 series dual-column gas chromatograph equipped for both FID and TCD was used. The esterified organic acids were resolved and identified with two different columns using both TCD and FID. A metal column $(1.83 \mathrm{~m} \times 6 \mathrm{~mm})$ packed with GP $10 \% \mathrm{SP}-1000 / 1 \% \mathrm{H}_{3} \mathrm{PO}_{4}$ on Chromosorb $100 / 120 \mathrm{~W} \mathrm{AW}$ (Supelco, Bellefonte, PA, USA) was preconditioned for $24 \mathrm{~h}$ at $180^{\circ} \mathrm{C}$ under helium flow. The flow rates for FID were 30,300 and $300 \mathrm{ml} \mathrm{min}^{-1}$ for hydrogen, air and helium, respectively. The injector port and detector temperatures were both $180^{\circ} \mathrm{C}$. Samples were chromatographed at $155^{\circ} \mathrm{C}$, with the attenuation set to $10^{-10}$. For TCD analysis on the same column, the helium flow rate was adjusted to $30 \mathrm{ml} \mathrm{min}{ }^{-1}$. The injector port and detector temperatures were set to $140^{\circ} \mathrm{C}$. The oven temperature was $125^{\circ} \mathrm{C}$, filament temperature was $240^{\circ} \mathrm{C}$, and the detector current was $625 \mathrm{~mA}$. A second metal column $(1.83 \mathrm{~m} \times 3 \mathrm{~mm})$ packed with GP $10 \% \mathrm{SP}-1200 / 1 \%$ $\mathrm{H}_{3} \mathrm{PO}_{4}$ on Chromosorb 80/100 W AW (Supelco) was also tested for separation of derivatized carboxylic acids via TCD. This column had also been preconditioned in the manner described. The helium gas flow rate was set at $20 \mathrm{ml} \mathrm{min}{ }^{-1}$, and both injector port and detector temperatures were lowered to $150^{\circ} \mathrm{C}$. All other settings for TCD analysis remained the same. In all cases, helium (ultra-high purity; Matheson, Secaucus, NJ, USA) was used as the carrier gas.

Preparation of standards. Organic acid standards were commercially purchased: glacial acetic acid (Mallinckrodt Inc., Paris, KY, USA); butyric acid, sodium salt (Matheson, Coleman \& Bell, Cincinnati, OH, USA); citric acid (Allied Chemical, Morristown, NJ, USA); formic acid, 89.7\% (J. T. Baker Chemical Co., Phillipsburg, NJ, USA); fumaric acid, $99+\%$ (Matheson, Coleman \& Bell); L-malic acid (Eastman Organic Chemicals); oxaloacetic acid (ICN Nutritional Biochemicals, Cleveland, OH, USA); succinic acid (Fisher Scientific). cis-Aconitate; glyoxylate, sodium salt, $98 \%$ pure; DL-isocitrate, trisodium salt; 2-oxoglutarate, monopotassium salt; propionate, sodium salt, type I; pyruvate, free acid, type I and sodium salt, type II were all obtained from Sigma. A standard mixture of organic acids was chromatographed to determine optimal conditions for HPLC separation. All standards were prepared in HPLC-grade water and stored at $-80^{\circ} \mathrm{C}$ to avoid decomposition. Since organic acids exhibit a wide range of extinction coefficients at $210 \mathrm{~nm}$, the concentration of each had to be adjusted so that all the acids would appear as distinguishable species. Preliminary experiments led to an optimal mixture of TCA cycle and fermentation acids (see Table 1) for all subsequent HPLC analysis. HPLC analysis revealed traces of fumarate in commercial samples of malic acid. 
Derivatization. For GLC analysis, volatile organic acids were extracted with ether (Holdeman et al., 1977) and chromatographed using either TCD or FID. Non-volatile acids were methylated in the $\mathrm{H}_{2} \mathrm{SO}_{4} /$ methanol mixture (Holdeman et al., 1977) and extracted with chloroform for TCD by the same procedure. Non-volatile acids were prepared for FID analysis by a modification of the procedure described by Harmon \& Doelle (1969). Samples $(2 \mathrm{ml})$ of filtered culture media were frozen to $-80^{\circ} \mathrm{C}$ and dried in a Freeze Dry 3 lyophilization unit, model 75200 (Labconco, Kansas City, MO, USA). Lyophilized samples were incubated in $3 \mathrm{ml} 14 \%(\mathrm{v} / \mathrm{v}) \mathrm{BF}_{3}(\mathrm{Sigma})$ in methanol overnight at $28^{\circ} \mathrm{C}$ to produce methyl esters, which were extracted with chloroform. Organic acid components were identified on the basis of retention rates and coelution with known standards.

Gas chromatography/mass spectroscopy. Analysis was done by electron-impact ionization ( $70 \mathrm{eV})$ on a Finnigan 4021 gas chromatograph/mass spectrometer (Finnigan Corp., Sunnyvale, CA, USA) equipped with a model 9610 Finnigan gas chromatograph. The ion source temperature was $200^{\circ} \mathrm{C}$. Samples of the media, derivatized by the $\mathrm{BF}_{3}$ procedure previously described, were chromatographed on a glass column $(1.83 \mathrm{~m} \times 6 \mathrm{~mm})$ packed with $10 \%$ SP-1000/1\% $\mathrm{H}_{3} \mathrm{PO}_{4}$ on Chromosorb $100 / 120 \mathrm{~W} \mathrm{AW}$. After injection, the column temperature was held at $155^{\circ} \mathrm{C}$ for $6 \mathrm{~min}$ and then increased to $185^{\circ} \mathrm{C}$ at a rate of $10^{\circ} \mathrm{C} \mathrm{min}-1$. This procedure decreased the elution time of the esterified acids, thereby minimizing product breakdown, e.g. the elution time for the methyl ester of malate was reduced from 48 to $17 \mathrm{~min}$. Fragments with a mass of 35 to 175 were scanned and the data were analysed by a Finnigan INCOS data system (revision $\mathrm{C}$ ). Compounds were identified by comparing retention time and mass spectrum of each peak with known standards.

\section{RESULTS}

Although many acids in the standard mixture (Table 1) could not be resolved by cationexchange HPLC at room temperature, increasing the temperature gave greater resolution (Fig. $1 a-c$ ). Raising the system temperature from $25^{\circ} \mathrm{C}$ (Fig. $1 a$ ) to $65^{\circ} \mathrm{C} \mathrm{(Fig.} 1 b$ ) improved the resolution of lactate and succinate, which had coeluted at the lower temperature, and malate was also separated from glyoxylate. However, 2-oxoglutarate, isocitrate, citrate, pyruvate and oxaloacetate were not separated into individual peaks. At $85^{\circ} \mathrm{C}$, isocitrate, oxaloacetate and succinate could be resolved (Fig. 1c), but 2-oxoglutarate and citrate coeluted, as did malate and pyruvate; the lactate and fumarate peaks overlapped. Above $85^{\circ} \mathrm{C}$ aqueous solvent systems were unstable because of evaporation and changing $\mathrm{pH}$.

Since the standard mixture of organic acids was most easily resolved at the highest temperature, further HPLC analysis was done at $85^{\circ} \mathrm{C}$. By reducing the concentration of the sulphuric acid mobile phase from 0.0045 M (Fig. 1c) to 0.00225 M (Fig. 2a), 2-oxoglutarate could be resolved from citrate. Pyruvate emerged as a separate peak from malate. Increased resolution was also observed for lactate and fumarate. A further decrease to $0 \cdot 001 \mathrm{M}-\mathrm{H}_{2} \mathrm{SO}_{4}$ of the mobile phase resulted in additional coelution of the acids (Fig. $2 b$ ), e.g. oxaloacetate coeluted with pyruvate. The addition of a second Aminex HPX-87H Bio-Rad organic acid analysis column,

Table 1. Concentration of organic acids in the final chromatographic mixture

Acid

Acetic (ACE) cis-Aconitic (ACO)

Butyric (BUT)

Citric (CIT)

Formic (FOR)

Fumaric (FUM)

Glyoxylic (GLY)

Isocitric (ISO)

2-Oxoglutaric (2-OG)

Lactic (LAC)

Malic (MAL)

Oxaloacetic (OAA)

Propionic (PRO)

Pyruvic (PYR)

Succinic (sUC)
Concn (M)

0.0614

0.00025

0.0825

0.0174

0.0534

0.00025

0.0177

0.0019

0.0036

0.0161

0.0135

0.0110

0.0298

0.0033

$\mathbf{0 . 0 3 0 0}$ 


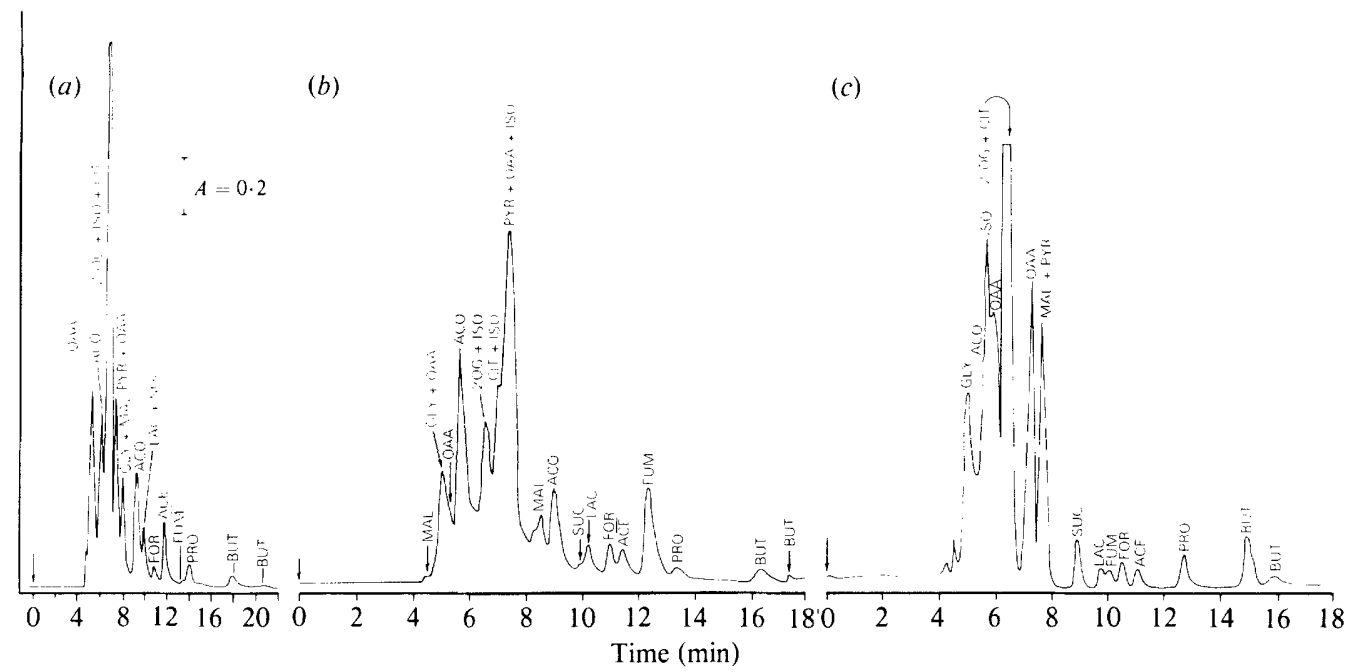

Fig. 1. Effect of varying column temperature on the resolution of a standard mixture of tricarboxylic acids by cation-exchange HPLC. (a) $25^{\circ} \mathrm{C},(b) 65^{\circ} \mathrm{C},(c) 85^{\circ} \mathrm{C}, \mathrm{H}_{2} \mathrm{SO}_{4}(0.0045 \mathrm{M})$ was used as the mobile phase for all three temperatures. See Table 1 for abbreviations.

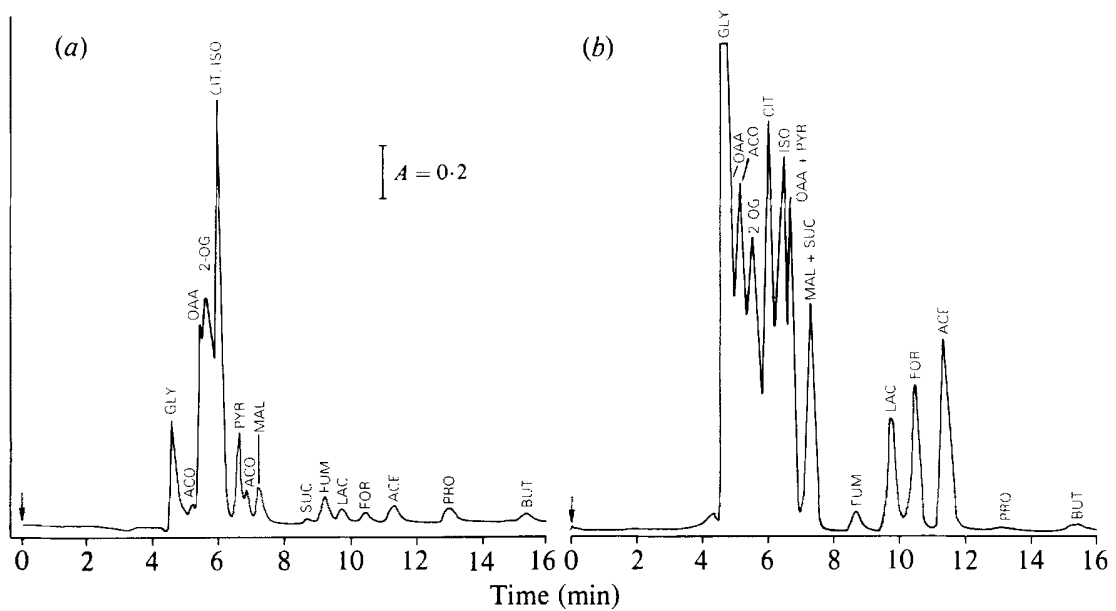

Fig. 2. Effect of varying mobile phase on the resolution of a standard mixture of TCA cycle and fermentation acids by cation-exchange HPLC. (a) $0.00225 \mathrm{M}-\mathrm{H}_{2} \mathrm{SO}_{4}$, (b) $0.001 \mathrm{M}-\mathrm{H}_{2} \mathrm{SO}_{4}$. Column temperature was maintained at $85^{\circ} \mathrm{C}$ for different mobile phase concentrations. See Table 1 for abbreviations.

connected in series to the first with a $10 \mathrm{~cm}$ column adaptor (Upchurch, Oak Harbor, WA, USA), did not improve resolution. Spent media of Azospirillum brasilense and Desulfovibrio desulfuricans were analysed, therefore, at $85{ }^{\circ} \mathrm{C}$ using $0.00225 \mathrm{M}-\mathrm{H}_{2} \mathrm{SO}_{4}$.

HPLC analysis of the spent $A$. brasilense medium at mid-exponential growth phase revealed the presence of fumarate and malate peaks, and a reduction in the size of the succinate peak (Fig. 3). Unidentified peaks represent components of the basal salts medium. Only acetate and traces of malate were observed in the spent culture medium of the anaerobic sulphate-dependent growth of $D$. desulfuricans. Most of the pyruvate remained in the medium (Fig. $4 a$ ). The modified Brandis-Thauer medium originally contained reducing agents which contribute additional peaks to the organic acid profile. Two of these were identified as ascorbic acid and thioglycollate (Fig. 4a). Replacing these organic reducing agents with sodium sulphide 


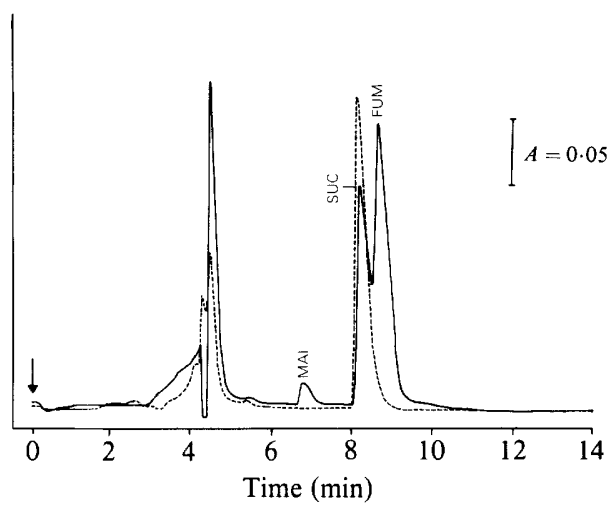

Fig. 3. HPLC analysis of the organic acid content of uninoculated (---) and spent ( - ) culture medium of $A$. brasilense under aerobic conditions. See Table 1 for abbreviations.
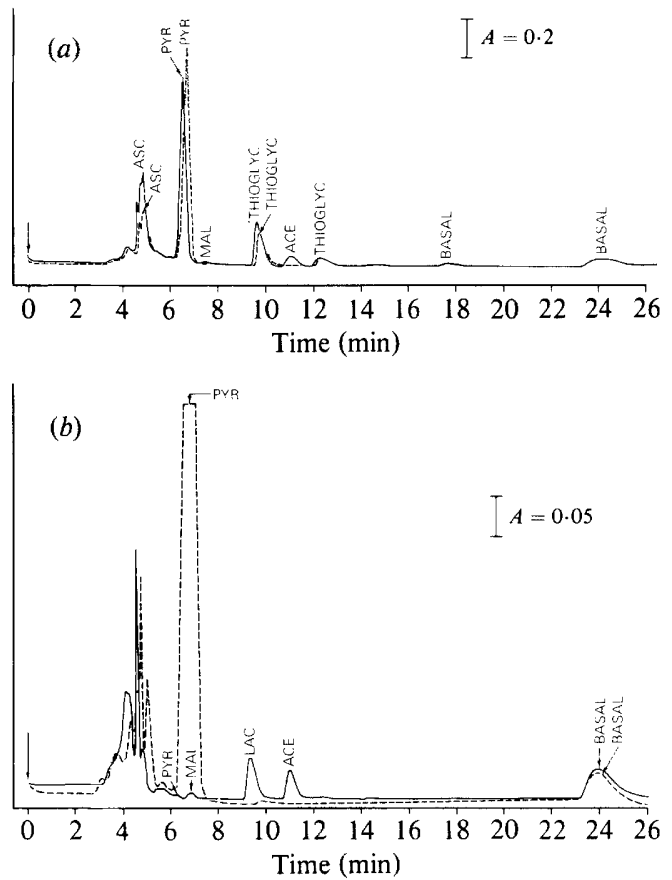

Fig. 4. HPLC analysis of the organic acid content of uninoculated (---) and spent ( - ) culture medium of $D$. desulfuricans under respiratory $(a)$ and fermentative $(b)$ conditions. See Table 1 for abbreviations (ASC, ascorbate; THIOGLYC, thioglycollate).

eliminated a number of interfering peaks. HPLC analysis of the fermentative medium of $D$. desulfuricans revealed the production of lactate, acetate and trace amounts of malate (Fig. $4 b$ ). Pyruvate was almost totally exhausted.

Samples of each of the above media were also analysed by GLC and GLC/MS. Both the $\mathrm{H}_{2} \mathrm{SO}_{4} /$ methanol and $\mathrm{BF}_{3} /$ methanol procedures for the derivatization of organic acids for GLC were tested; the $\mathrm{BF}_{3} /$ methanol derivatization was used to prepare samples for GLC/MS analysis. The results of all four types of analysis are summarized in Table 2. HPLC analysis of the spent culture medium of $A$. brasilense $\mathrm{Sp} 7$ had shown the presence of succinate, fumarate and malate. In addition to these acids, trace amounts of pyruvate were also detected by GLC/MS. 
Table 2. Identification of TCA cycle and fermentation acids by HPLC, GLC (using both acid) methanol and $B F_{3} /$ methanol derivatization procedures) and $G L C / M S$

See Table 1 for abbreviations. -, Not detected.

\begin{tabular}{|c|c|c|c|c|}
\hline \multirow[b]{2}{*}{$\begin{array}{l}\text { Spent culture } \\
\text { medium }\end{array}$} & \multicolumn{3}{|c|}{ GLC } & \multirow[b]{2}{*}{ GLC/MS } \\
\hline & HPLC & $\begin{array}{l}\mathrm{H}_{2} \mathrm{SO}_{4} / \\
\text { methanol }\end{array}$ & $\begin{array}{c}\mathbf{B F}_{3} / \\
\text { methanol }\end{array}$ & \\
\hline \multirow{5}{*}{$\begin{array}{c}\text { Azospirillum } \\
\text { brasilense }\end{array}$} & suC & suc & SUC & SUC \\
\hline & FUM & FUM* & - & FUM* \\
\hline & MAL & $\mathrm{MAL}^{*}$ & MAL* & MAL* \\
\hline & - & - & PYR* & PYR* \\
\hline & - & - & LAC* & - \\
\hline \multirow{6}{*}{$\begin{array}{l}\text { Desulfovibrio } \\
\text { desulfuricans } \\
\text { (fermentative) }\end{array}$} & PYR & PYR & PYR & PYR \\
\hline & $\mathrm{ACE}$ & ACE & $\mathrm{ACE}$ & - \\
\hline & LAC & - & LAC & LAC \\
\hline & MAL* & - & - & - \\
\hline & - & $\mathrm{OAA}^{*}$ & - & - \\
\hline & - & - & - & suC* \\
\hline \multirow{5}{*}{$\begin{array}{l}\text { Desulfovibrio } \\
\text { desulfuricans } \\
\text { (respiratory) }\end{array}$} & PYR & PYR & PYR & PYR \\
\hline & ACE & ACE & ACE & - \\
\hline & MAL* & - & - & - \\
\hline & - & OAA $†$ & - & - \\
\hline & - & - & LAC* & - \\
\hline
\end{tabular}

* Trace amounts. † Artefact of derivatization generated from pyruvate.

Malate could only be detected with the SP-1200 column and fumarate could only be detected with the SP-1000 column using the $\mathrm{H}_{2} \mathrm{SO}_{4}$ /methanol derivatization procedure. Fumarate was not detected by the $\mathrm{BF}_{3} /$ methanol procedure. Pyruvate was detected by GLC and GLC/MS only when the culture medium was derivatized by $\mathrm{BF}_{3} /$ methanol. Traces of lactate were observed when the $\mathrm{BF}_{3} /$ methanol procedure was used for GLC analysis.

HPLC analysis detected the presence of pyruvate, acetate, lactate and traces of malate in spent fermentative growth medium of $D$. desulfuricans. Pyruvate, lactate and traces of succinate were detected by GLC/MS, whereas pyruvate, lactate and acetate were also detected by GLC using the $\mathrm{BF}_{3} /$ methanol derivatization procedure. Acetate standards could not be detected using the described conditions for GLC/MS. Lactate could not be detected by GLC analysis using the $\mathrm{H}_{2} \mathrm{SO}_{4} /$ methanol procedure. None of the procedures which rely on prior derivatization could detect malate in the culture medium. Traces of succinate were detected in the fermentative medium by GLC/MS analysis only.

HPLC analysis showed that no lactate was produced during anaerobic respiration. All four methods tested detected pyruvate and acetate, but malate could only be assayed by HPLC. Traces of lactate were only detected by GLC analysis using the $\mathrm{BF}_{3} /$ methanol derivatization procedure.

\section{DISCUSSION}

With the exception of citrate and isocitrate, all TCA cycle and fermentation acids tested could be resolved by cation-exchange HPLC on an HPX-87H Bio-Rad column with a $0.00225 \mathrm{M}-$ sulphuric acid mobile phase at $85^{\circ} \mathrm{C}$. Those two TCA cycle acids were separated by reducing the concentration of the mobile phase to $0.001 \mathrm{M}$. Thus, a complete organic acid profile could be generated in two runs, each lasting approximately $16 \mathrm{~min}$. The addition of a second column did not improve resolution. The increased retention time (approx. $40 \mathrm{~min}$ ), which had also been observed in other multiple column systems (Buchanan \& Thoene, 1982), made this an unattractive procedure as a rapid and reproducible technique.

The concentration of each organic acid in the optimal mixture was very close to the lower limits of detection by cation-exchange HPLC. Although organic acids could be detected at lower 
concentrations than those shown in Table 1, when a single standard was chromatographed, the concentrations indicated in Table 1 reflected more realistic detection limits in the analysis of mixtures of organic acids in spent culture media. The sensitivity of this procedure meant that the HPLC had to be recalibrated for each analysis. The quantification of sample mixtures was not within the scope of the present work. A comparison of the results obtained by each of the four methods tested showed that cation-exhange HPLC is particularly suitable for the detection of malate and fumarate. However, this technique could not detect trace amounts of lactate, pyruvate and succinate in the culture media.

The GLC detection of fumarate and malate was difficult using the $\mathrm{H}_{2} \mathrm{SO}_{4} /$ methanol derivatization procedure. Detection varied depending on the column packing material used to separate the acids. Using the $\mathrm{H}_{2} \mathrm{SO}_{4} /$ methanol derivatization procedure, an additional peak which coeluted with oxaloacetate standards was consistently found in esterified samples of culture media containing pyruvate. It has been suggested that commercial pyruvate samples are contaminated with oxaloacetate (Holdeman et al., 1977). However, methylation of pyruvate has been shown to produce multiple esterification products (Simmonds et al., 1967; Hautala \& Weaver, 1969). HPLC analysis of pyruvate standards and culture media samples containing pyruvate showed that oxaloacetate was not present as a contaminant.

Compared to the previous techniques, GLC analysis of culture media derivatized by the $\mathrm{BF}_{3} /$ methanol procedure was particularly sensitive for pyruvate and lactate. Some of these differences observed by GLC analysis may be due to the high temperature and acidity of the $\mathrm{H}_{2} \mathrm{SO}_{4} /$ methanol procedure, resulting in sample loss. In addition, the differences in the mode of detection cannot be ignored. The $\mathrm{H}_{2} \mathrm{SO}_{4} /$ methanol procedure was developed for TCD, while FID is the method described for the $\mathrm{BF}_{3} /$ methanol derivatization procedure.

Trace amounts of malate, lactate and succinate were detected depending on the choice of derivatization procedure and the mode of detection. The conditions for GLC/MS, using electron impact ionization, could not identify standards or samples containing acetate. However, this procedure was the most sensitive in detecting trace amounts of succinate. Using identical derivatization procedures and GLC conditions, the MS detector did not identify trace amounts of lactate which had been assayed by FID. Conversely, FID did not reveal the presence of fumarate which had been shown by MS analysis.

During fermentative growth of $D$. desulfuricans, pyruvate was exhausted and acetate and lactate accumulated in the medium. Trace amounts of succinate and malate were also detected depending on the mode of detection and mode of growth. Compared to fermentative growth, $D$. desulfuricans utilized much less pyruvate during anaerobic respiration. Pyruvate and lactate as well as traces of fumarate and malate in the spent medium of $A$. brasilense were present as products formed from succinate oxidation. The verification of enzymes of organic acid metabolism in the test organisms is beyond the scope of the present paper.

Of the four methods tested, MS was expected to be the most sensitive: modern instruments can detect single ions arriving at the ion-collection system (Willard et al., 1965). Flame ionization is considered to be a very sensitive GLC detection mode by virtue of its low background noise level $\left(10^{12} \mathrm{~A}\right)$ and linear dynamic range of $10^{7}$. Although the mechanism of the thermal ionization detection is still under debate, its limit of resolution for alkanes is $2 \times$ $10^{-11} \mathrm{~g}$ (McNair \& Bonelli, 1969). In contrast, the limit of resolution for the detection of methane by thermal conductivity is $10^{-5} \mathrm{~g}$.

For HPLC analysis, the limit of resolution by optical absorbance in the ultraviolet range can approach $10^{-9} \mathrm{~g}$ (Johnson \& Stevenson, 1978). However, the choice of a wavelength represents a compromise between the optical properties of the sample and background absorption by the solvent. The carboxyl chromophore of organic acids has a weak absorption band near $200 \mathrm{~nm}$ due to a $\mathrm{n} \rightarrow \pi^{*}$ transition by the valence electrons (Silverstein et al., 1974). The shortest wavelength at which organic acid samples were readily distinguishable from background noise was $210 \mathrm{~nm}$.

Cation-exchange HPLC proved to be a rapid and reliable method for separating and detecting organic acids in culture media. The ease of sample preparation favours the use of this technique over both GLC and GLC/MS, because sample extraction and derivatization are not 
required. None of the four techniques used, however, was inherently superior in the detection of trace amounts of organic acids in spent culture media. Thus, use of a single technique cannot rule out the possibility that trace organic acids are present.

We are grateful to Ms M. A. Siefert for excellent advice and assistance in the mass spectral analysis of organic acids. We also thank the graphics illustrators, College of Biological Sciences, for preparing HPLC chromatograms for publication and Beverly Reid for typing the manuscript.

\section{REFERENCES}

Behbehani, M. J., Jordan, H. V. \& Santoro, D. L. (1982). Simple and convenient method for culturing anaerobic bacteria. Applied and Environmental Microbiology 43, 255-256.

Bocek, P., Lekova, K., Deml, M. \& JaNaK, J. (1976). Separation of some typical Krebs cycle acids by high-speed isotachophoresis. Journal of Chromatography 117, 97-104.

Brandis, A. \& Thauer, R. K. (1981). Growth of Desulfovibrio species on hydrogen and sulphate as sole energy source. Journal of General Microbiology 126, 249-252.

Buchanan, D. N. \& Thoene, J. G. (1982). Dualcolumn high-performance liquid chromatographic urinary organic acid profiling. Analytical Biochemistry 124, 108-116.

DaJANi, R. M. \& OrTEn, J. M. (1958). A study of the citric acid cycle in erythrocytes. Journal of Biological Chemistry 231, 913-924.

DelmotTE, P. (1979). Capillary isotachophoresis. Journal of Chromatography 165, 87-101.

Frohman, C. E., Orten, J. M. \& SMith, A. H. (1951). Chromatographic determination of the acids of the citric acid cycle in tissues. Journal of Biological Chemistry 193, 277-283.

Guerrant, G. O., Lambert, M. A. \& Moss, C. W. (1982). Analysis of short-chain fatty acids from anaerobic bacteria by high-performance liquid chromatography. Journal of Clinical Microbiology 16, $355-360$.

Harmon, M. A. \& Doelle, H. W. (1969). Gas chromatographic separation and determination of microquantities of the esters of the tricarboxylic acid cycle acids and related compounds. Journal of Chromatography 42, 157-169.

Hautala, E. \& Weaver, M. L. (1969). Separation and quantitative determination of lactic, pyruvic, fumaric, succinic, malic, and citric acids by gas chromatography. Analytical Biochemistry 30, 32-39.

Holdeman, L. V., Cato, E. P. \& Moore, W. E. C. (eds.). (1977). Anaerobic Laboratory Manual, 4th edn. Blacksburg, VA: Virginia Polytechnic Institute \& State University.

Horning, M. G., Boucher, E. A., Muss, A. M. \& HorNing, E. C. (1968). Gas chromatographic study of derivatives of acids of the Krebs cycle and related compounds. Analytical Letters 1, 713-723.

Johnson, E. L. \& STEvenson, R. (1978). Basic Liquid Chromatography. Palo Alto: Varian Instruments.

Jorgenson, J. W. \& LukACs, K. D. (1983). Capillary zone electrophoresis. Science 222, 266-272.

KNAPP, D. R. (1979). Handbook of Analytical Derivatization Reactions. New York: Wiley.

LAMBERT, M. A. \& Moss, C. W. (1972). Gas-liquid chromatography of short-chain fatty acids on Dexsil 300GC. Journal of Chromatography 74, 335-338.

Marsili, R. T., Ostapenko, H., Simmons, R. E. \& GreEN, D. E. (1981). High performance liquid chromatographic determination of organic acids in dairy products. Journal of Food Science 46, 5256.

McNair, H. M. \& Bonelli, E. J. (1969). Basic Gas Chromatography, 5th edn. Berkeley: Consolidated Printers.

Meuzelaar, H. L. C., Kistemaker, P. G., SchutGens, R. B. H., Veder, H. A., Cardinal, J. R., Bowers, J. H. \& ANToschechKin, A. G. (1980). Fast, quantitative profiling of urine, bile, and fibroblast samples by pyrolysis-mass spectrometry. In Current Developments in the Clinical Applications of $H P L C, G C$ and $M S$, pp. 209-231. Edited by A. M. Lawson, C. K. Lim \& W. Richmond. London: Academic Press.

RAJAKYLÄ, E. (1981). Separation and determination of some organic acids and their sodium salts by highperformance liquid chromatography. Journal of Chromatography 218, 695-701.

Silverstein, R. M., Bassler, G. C. \& Morril, T. C. (1974). Spectrometric Identification of Organic Compounds, 3rd edn. New York: Wiley.

Simmonds, P. G., Pettitt, B. C. \& Zlatkis, A. (1967). Esterification, identification, and gas chromatographic analysis of Krebs cycle keto acids. Analytical Chemistry 39, 163-167.

TURKELSON, V. T. \& RiChaRdS, M. (1978). Separation of the citric acid cycle acids by liquid chromatography. Analytical Biochemistry 50, 1420-1423.

Willard, H. H., MerritT, L. L. \& Dean, J. A. (1965). Instrumental Methods of Analysis, 4th edn. New York: Reinhold Van Nostrand. 